\title{
PORTFÓLIO COMO ESTRATÉGIA DE AVALIAÇÃO DE ESTUDANTES DE ODONTOLOGIA
}

\author{
PORTFOLIO AS A STRATEGY TO EVALUATE DENTISTRY STUDENTS
}

PORTAFOLIO COMO ESTRATEGIA DE EVALUACIÓN DE ESTUDIANTES DE ODONTOLOGÍA

\author{
Franklin Delano Soares Forte ${ }^{1}$ \\ Camila Helena Machado da Costa ${ }^{2}$ \\ Talitha Rodrigues Ribeiro Fernandes Pessoa ${ }^{3}$ \\ Annatália Meneses de Amorim Gomes ${ }^{4}$ \\ Claudia Helena Soares Morais Freitas ${ }^{5}$ \\ Liberata Campos Coimbra $^{6}$ \\ Dorlene Maria Cardoso de Aquino ${ }^{7}$
}

Resumo O estudo teve por objetivo compreender a percepção de estudantes do curso de Odontologia da Universidade Federal da Paraíba sobre a utilização do portfólio como um dos métodos de avaliação. Os dados referentes a 16 estudantes foram coletados em 2011 por meio da técnica do grupo focal e submetidos à análise de conteúdo. Definiram-se, então, as categorias temáticas: conceituação, papel do discente-docente, metodologias ativas, dificuldades na elaboração do portfólio e sugestões. Os estudantes compreendem o portfólio como instrumento de diálogo entre docentes e discentes, por meio dos relatos das vivências em grupo nos equipamentos sociais e reflexões individuais na construção de conceitos e aprofundamento teórico. Conclui-se que os estudantes percebem o portfólio como ferramenta potente e inovadora para a formação profissional, constituindo-se instrumento de acompanhamento do processo de ensino-aprendizagem, por ser dialógico, interativo, oportunizando uma aprendizagem ativa.

Palavras-chave formação; portfólio reflexivo; avaliação formativa; metodologias de ensino-aprendizagem.
Abstract The study aimed to understand the perception Dentistry students at the Federal University of Paraíba have of the use of portfolios as one of the evaluation methods. Data were collected from 16 students in 2011 by means of the focus group technique and were analyzed based on content analysis. The themes were then defined: conceptualization, student-professor role, active methods, difficulties in preparing portfolios and suggestions. Students see portfolios as an instrument of dialog between professors and students through accounts of group experiences in the social equipment and individual reflections in the construction of concepts and theoretical deepening. It was concluded that students perceive the portfolio as a powerful, innovative tool for vocational training, serving to monitor the teaching-learning process for being dialogical, interactive, and providing opportunities for active learning.

Keywords training; reflexive portfolio; formative assessment; teaching and learning methodologies. 


\section{Introdução}

Na área da saúde, têm-se apontado caminhos inovadores para a formação e capacitação de profissionais; adotam-se, então, novas formas de ensino-aprendizagem e de organização curricular na perspectiva de desenvolver a capacidade de reflexão sobre problemas reais e a formulação de ações originais e criativas capazes de transformar a realidade social (Mitre et al., 2008; Teófilo e Dias, 2009; Marin et al., 2010a).

Nesse contexto, vêm ganhando destaque as metodologias ativas de aprendizagem que podem ser traduzidas por uma prática pedagógica democrática baseada em princípios de liberdade, autonomia, igualdade, equidade, fraternidade e compaixão (Mitre et al., 2008). Para efetivá-las, é preciso apostar em uma educação que desenvolva processos críticos de ensino-aprendizagem, utilizando-se estratégias inovadoras que estimulem o pensamento reflexivo (Cotta, Mendonça e Costa, 2011).

O portfólio surge então como uma estratégia no uso de metodologias ativas, na qual professor e estudante transformam a sua forma de ver, pensar e agir, apresentando real impacto na motivação e aprendizagem significativa (Cotta, Mendonça e Costa, 2011). Responde ainda ao desafio imposto às novas práticas educativas, no que diz respeito à avaliação formativa representada por um processo contínuo, dialógico, diagnóstico e participativo (Gomes et al., 2010).

O curso de Odontologia da Universidade Federal da Paraíba (UFPB) passou por várias adequações em sua proposta pedagógica ao longo de mais de sessenta anos e desde 2002 foi proposto, com base nas diretrizes curriculares nacionais (DCN), o seu Projeto Pedagógico (Brasil, 2002). Nesse contexto, destacamos os estágios supervisionados obrigatórios dos dois primeiros anos do curso, que adotaram a proposta pedagógica das metodologias ativas, incluindo, dessa forma, processos inovadores no aprender e ensinar, orientados pelo desenvolvimento esperado do perfil do egresso no contexto regional e nacional. Nessa perspectiva, de natureza reflexiva e crítica, a partir de vivências em Unidades de Saúde da Família (USF) em seu território com base na problematização desse contexto, procura-se a construção de concepções, ideias, valores e conhecimento no campo da saúde coletiva.

Os cenários de prática dos estágios supervisionados do Curso de Odontologia da UFPB são as USF e seus equipamentos sociais no território. Os atores nesse movimento são os estudantes, docentes e trabalhadores da rede de serviço de saúde que articulam ações intersetoriais, para além da saúde, ações desenvolvidas em conjunto com outros saberes, competências presentes em outras áreas de conhecimento. Reconhece-se, assim, o território, valorizam-se as potencialidades locais e, sobretudo, possibilita-se a aproximação dos estudantes aos contextos socioeconômicos e culturais de famílias e da comunidade, além da realidade do trabalho em saúde. 
Na perspectiva de uma abordagem pedagógica que priorize as metodologias ativas, os portfólios foram adotados como ferramenta de acompanhamento e avaliação dos estudantes nos componentes curriculares e estágios supervisionados dos dois primeiros anos do curso. Os estudantes, ao elaborarem seu portfólio, podem registrar ações, tarefas, resenhas, sínteses e a própria aprendizagem, por meio de um discurso narrativo elaborado de forma contínua e reflexiva.

A confecção do portfólio reflexivo, com a intenção da ponderação da prática diária do pensar e dissertar, traz consigo o processo de reflexão crítica continuada que os estudantes por si mesmos explicam como constroem a sua aprendizagem, relatam as vivências, dialogam com os problemas e superam as dificuldades, bem como a relação entre teoria e prática (Rangel, 2003; Villas Boas, 2005; Marcolino e Mizukami, 2008; Silva e Sá-Chaves, 2008; Tanji e Silva, 2008; Silva e Francisco, 2009; Marin et al., 2010b; Cotta, Mendonça e Costa, 2011).

O portfólio pode ser definido não apenas como uma compilação dos trabalhos efetuados pelos estudantes, mas sim um relevante processo das análises críticas das experiências vivenciadas (Rangel, 2003; Villas Boas, 2005; Silva e Sá-Chaves, 2008; Tanji e Silva, 2008).

Os métodos ativos de aprendizagem necessitam de processos avaliativos igualmente coerentes com o novo perfil profissional. Assim, a educação precisa voltar-se para a formação de profissionais de saúde capazes de participar do processo de transformação da sociedade de maneira crítica e flexiva (Gonzáles e Almeida, 2010; Marin et al., 2010a).

O presente estudo teve como propósito compreender a percepção de estudantes do curso de Odontologia da UFPB sobre a utilização do portfólio como instrumentos de avaliação e acompanhamento do processo de ensino-aprendizagem.

\section{Percurso metodológico}

É um estudo exploratório com abordagem qualitativa, realizado com estudantes de graduação do curso de Odontologia da UFPB, no ano de 2011. A opção dessa abordagem foi em função do objeto do estudo, oportunizando visualizar as significações e valores, conceitos (Minayo, 2010). As percepções vão sendo expostas e a discussão pode provocar modificações conforme a intervenção dos sujeitos envolvidos. Com isso, permite-se a elaboração de ideias e de conceitos baseados em valores, expectativas e atitudes moderados por um sujeito (Minayo, 2010).

Neste estudo utilizou-se como técnica de coleta de dados o grupo focal, com um roteiro de orientação para discussão. A amostra dos participantes 
foi intencional, utilizando os seguintes critérios: vivenciaram os Estágios Supervisionados I, II, III, IV do curso de Odontologia da UFPB na atenção primária nos dois primeiros anos do curso; e utilizaram o portfólio como instrumento pedagógico de acompanhamento e avaliação nesses componentes curriculares. O grupo foi composto por 16 participantes, de ambos os sexos, cuja idade variou entre 16 e 23 anos.

As discussões no grupo focal foram orientadas por um roteiro semiestruturado e moderadas por um docente-pesquisador. As questões norteadoras foram: O que é o portfólio? Quais os objetivos do portfólio? Como foram construídos os seus portfólios? Quais as dificuldades enfrentadas na construção do seu portfólio? Quais os pontos positivos e negativos do uso do portfólio? Em que o portfólio reflexivo contribui para o processo de aprendizagem de vocês? Quais as diferenças encontradas entre as metodologias ativas e a tradicional? Quais as dificuldades encontradas na implantação dessa nova forma de avaliação? Quais as dificuldades encontradas para o professor? Quais as suas sugestões?

Foram realizados dois encontros com o grupo, com duração média de 60 minutos em 2011. O facilitador estimulou a participação livre de todos os integrantes do grupo focal (Stewart e Shamdasani, 2007). Os momentos do grupo focal foram registrados em áudio (gravados em mp5), tendo sido posteriormente transcritos e, na sequência, realizada a leitura-análise exaustiva das transcrições.

Para interpretação dos dados, utilizou-se a proposta da análise de conteúdo de Bardin (2009). As transcrições foram lidas e relidas, procurando-se, assim, ordenar o conteúdo, reestruturar as ideias e pontos chave do material (Bardin, 2009). As categorias foram predefinidas a partir da leitura de Villas Boas, 2005; Marin et al., 2010b; Silva e Francisco, 2009; Silva e Sá-Chaves, 2008; Tanji e Silva, 2008; as quais são: conceituação, papel do discente-docente, metodologias ativas, dificuldades na elaboração do portfólio e sugestões.

Observando as questões éticas inerentes à pesquisa com seres humanos, este projeto foi submetido e aprovado no Comitê de Ética em Pesquisa com Seres Humanos do Hospital Universitário Lauro Wanderley da UFPB, seguindo todas as orientações da resolução n. 196/96 do Conselho Nacional de Saúde. Todos os participantes assinaram o termo de consentimento livre e esclarecido.

\section{Discussão dos resultados}

A seguir serão descritas as categorias e as falas dos estudantes no grupo focal: conceituação, papel do discente-docente, metodologias ativas, dificuldades na elaboração do portfólio e sugestões. Nessas categorias, embora 
descritas aqui isoladamente, são articuladas as vivências e a construção do portfólio pelos alunos e leitura pelos docentes.

\section{Conceituação}

O portfólio é compreendido pelos estudantes como instrumento de reflexão, onde é possível relatar as experiências das vivências no território das USF, assegurando a construção do conhecimento. A orientação dos docentes dos estágios supervisionados, para a construção do portfólio reflexivo, é de que o estudante documente, registre as ações, as tarefas e a própria aprendizagem por meio de um discurso narrativo sobre as atividades educacionais vivenciadas. Nesta pesquisa, os estudantes entendem também o portfólio como um diário ou um legado, que vai sendo construído diariamente, pautado no sentimento e na construção do conhecimento. Além do mais, permite depois de um tempo repensar as ideias e as impressões de mundo ao reler as experiências relatadas no portfólio e, com isso, poder observar as transformações, facilitando o aprendizado a partir da reconstrução.

(...) é um instrumento onde a gente pode relatar as experiências vivenciadas nos estágios (...) oportunidade de relatar minhas vivências, dificuldades e aprendizados.

(...) o portfólio sempre pôde mais que uma prova. Foi com ele que firmamos nossos aprendizados, foi nele que pudemos desabafar quando uma atividade não superou as nossas expectativas e não saiu como planejado, foi nele que colocamos carinho, atenção, que depositamos um cuidado todo especial.

(...) depois de um tempo, se você reler, vai perceber o que mudou, o que você melhorou.

Com certeza agora conseguimos entender melhor seu objetivo e seus benefícios para a nossa aprendizagem. Posso dizer que o portfólio estimula nossa reflexão, fazendo com que nós possamos parar e relembrar tudo que vivemos, aprendemos e aplicamos, relacionando a teoria com a prática, sempre.

Ao mesmo tempo o portfólio reflexivo provoca mudança em como as pessoas compreendem a si próprias e aos outros, assim como as situações que acontecem; ao ler seu escrito, é possível ir teorizando a própria experiência, na busca de construção de uma identidade profissional. Nesse sentido, o registro no portfólio pode expressar as dificuldades enfrentadas pelos estudantes, a identificação de conceitos equivocados e insuficientes, permite ao docente uma intervenção e ao estudante uma resignificação do elaborado (Gomes et al., 2010). 
O portfólio é uma ferramenta do processo de ensino-aprendizagem, apontado como item de maior representatividade, oferecendo uma estrutura que permite refletir e desenvolver atitudes e habilidades (Tanji e Silva, 2008), pois o escrito, a partir do vivido, experimentado, do realizado e do acontecido, é representações que auxiliam o aprendizado (Marin et al., 2010b). Cotta, Mendonça e Costa (2011) verificaram que o uso de portfólios coletivos, na disciplina de políticas de saúde, como avaliação e estímulo à aprendizagem significativa, instigou nos discentes a reflexão sobre o vivenciado e que foi considerada uma estratégia inovadora.

O grupo relatou que a produção do portfólio é baseada no planejamento, seguido do registro no instrumento. Nos estágios supervisionados, a reflexão sobre o cotidiano do trabalho nas USF e a prática baseada nesse território oportuniza ao estudante a elaboração de novos significados e sentidos. Procura-se estimular a resolução criativa dos problemas vivenciados, tentando compreender os limites, as opções de enfrentamento e as dificuldades de sua própria ação e da questão em si, subsidiando a tomada de decisão. Esse movimento é importante, pois provoca no estudante o desejo de aprender mais e assim criar processos significativos para si e para o grupo.

Os estudantes apontaram a melhoria no desempenho das atividades realizadas, a visualização da evolução dos trabalhos, a possibilidade de verificação dos erros e análise mais aprofundada dos problemas e, consequentemente, a implicação de soluções alternativas. Dessa forma, oportuniza-se a reflexão da prática, a teorização dos conceitos, a relação teoria e prática, provocando o pensamento crítico. O portfólio oferta a possibilidade de se refazer o pensamento do antes e do agora. Além disso, no portfólio pode-se expressar livremente com sentimento e expor a sensibilidade. Cotta, Mendonça e Costa (2011) apontaram que a construção do portfólio assegurou aos discentes o aprendizado no grupo e individual, a partir do exercício da autonomia e na tomada de decisões.

\section{Papel do discente-docente, metodologias ativas}

O portfólio aproxima o docente desse processo ensino-aprendizagem. Além disso, permite o diálogo entre docentes e discentes, possibilitando a apreciação de percepções e ideias a partir do agir na prática de campo (Gomes et al., 2010).

(...) porque você vai escrever os seus sentimentos, as suas reflexões, e não simplesmente as vivências que você teve.

(...) você vai partilhar suas experiências não com um professor, mas com um amigo que tá te orientando. 
Por meio do portfólio pudemos manter uma comunicação melhor com nossos professores, expor nossas opiniões, sem passar pela mesma pressão que é fazer uma prova.

O ensinar e o aprender nos estágios supervisionados foram vistos como processos indissociáveis, onde o professor deve agir facilitando o processo, provocando no aluno a reflexão. Dessa forma, evidencia-se que cada ator tem sua função de responsabilidade no processo de aprendizagem. Na utilização de métodos ativos de aprendizagem, evidencia-se a necessidade de mudança no papel do estudante, que precisa assumir a responsabilidade pela própria aprendizagem, conforme apontado nas DCNs (Brasil, 2002). Para Cotta, Mendonça e Costa (2011), o trabalho com o portfólio requer capacitação dos próprios docentes, os quais devem passar pela experiência de 'aprender fazendo'.

Os docentes envolvidos nos estágios supervisionados realizaram capacitações em cursos de metodologia ativas financiados pelo Pró-Saúde da Odontologia, além de fazerem o curso de ativadores do processo de mudanças na formação de profissionais de nível superior pela Escola Nacional de Saúde Pública Sergio Arouca - Fundação Oswaldo Cruz (Ensp-Fiocruz).

No processo de aprendizagem ativa, o estudante deve ser capaz de propor questionamentos que tenham relevância para o contexto, além de solucioná-los por meio de buscas em diferentes fontes, considerando a necessidade de trazer respostas confiáveis e atualizadas a serem confrontadas nos grupos de discussões (Marin et al., 2007; Marin et al., 2010a; Gomes et al., 2010).

Em pesquisa realizada por Gonzáles e Almeida (2010), o processo de ensino-aprendizagem foi citado como uma dificuldade para a ressignificação do papel do professor e do aluno. O processo visto de forma dissociada faz com que o professor se exima de suas responsabilidades com a aprendizagem e assuma apenas seus deveres com o ensino. O mesmo ocorre com o estudante, que se isenta de seus deveres no processo de ensino.

\section{Dificuldades na elaboração do portfólio}

Entre as dificuldades enfrentadas no processo de construção do portfólio, os estudantes falaram da falta de conhecimento do que vem realmente a ser o portfólio e qual a sua real importância; da complexidade de se colocar numa folha de papel tudo o que se pensa e o que se vive; a falta de coragem e a dificuldade em escrever e se expressar, como também explicitaram dificuldades na reflexão das vivências; e a responsabilidade da entrega do instrumento.

(...) a dificuldade é colocar num papel tudo aquilo que você pensa. 
Eu acho que o aluno não tem a dimensão do portfólio, de sua importância, pelo menos eu não tinha. Eu via o portfólio como algo avaliativo e não tinha a visão que era uma coisa tão pessoal.

Cotta, Mendonça e Costa (2011) destacaram que os objetivos do portfólio nesse processo devem ser bem compreendidos tanto pelo docente quanto pelo discente, sendo um desafio para esses atores o exercício da produção do portfólio e da leitura cuidadosa do portfólio.

Foi apontado o atraso da entrega do portfólio por parte dos alunos; as diferenças entre as várias formas de escrever, uma vez que existem vocações e personalidades distintas; e o questionamento por parte do discente e do docente se o aluno está realizando a atividade para receber uma "nota" ou se é feito com objetivo de reflexão sobre o vivenciado.

Alguns autores entendem o portfólio como um potente instrumento de aprimoramento das ações desenvolvidas em campo. Especialmente, porque oportuniza a reflexão e crítica sobre os problemas do cotidiano (Gomes et al., 2010; Villas Boas, 2005).

(...) a forma que ele escreveu foi uma forma diferente dos outros colegas, a oportunidade dele entender foi diferente. Não é que ele está certo e a gente tá errada.

Se você pegar todo mundo do grupo vai ser a mesma atividade, mas se você pegar o portfólio de cada um, cada um vai ter uma opinião diferente.

Em relação à viabilidade de troca da avaliação 'tradicional' somativa pelo portfólio, os alunos mostraram-se favoráveis, apontando que é uma forma diferente de avaliação, mas que o aluno deve fazê-lo sem necessariamente esperar algo em troca, encarando o portfólio de forma mais pessoal. Todavia, alguns apontaram a supervalorização da nota e a dificuldade de fazer o discente estudar sem a realização da prova.

(...) é uma forma de avaliação através de um critério mais amplo, já que apenas não só conhecimentos são avaliados, mas experiências, vivências e o modo de enxergar essas vivências.

(...) você deve fazer o portfólio como experiência e não para obter nota (...) porque aqui só quer saber de nota e eu acho isso errado.

(...) o portfólio veio então como uma dinâmica e, provável, melhor maneira de avaliação, pois nele relatamos de forma pessoal o que foi aprendido e absorvido sobre determinada aula. De forma gradativa e diária a avaliação é feita e com nossas próprias palavras expomos a nossa experiência individual no processo de 
busca e investigação do que foi exposto pelos professores, um excelente remédio para os tensionamentos provocados pelos exames; o portfólio, apesar de parecer melhor do que periódicas provas, não deve estar ligado ao descompromisso nem à desvinculação com a análise por parte dos professores com seus alunos.

(...) o último portfólio eu pude voltar a ver todas as outras atividades. À medida que o tempo passa, aprendemos coisas novas e é sempre gratificante passar para os outros o aprendizado.

Observou-se no grupo focal a necessidade de uma avaliação tida como 'tradicional', ou seja, a compreensão de que o estudo e o aprofundamento nos temas não se dá na construção do portfólio. Esse é um desafio para a docência quando da adoção das metodologias ativas para o trabalho pedagógico de ensinar e avaliar esse processo. No estudo de Gonzáles e Almeida (2010) observou-se que uma parcela dos estudantes pensa que a avaliação 'tradicional' é necessária e é tida como instrumento de estímulo à participação e ao compromisso do estudante. Abandonar o já conhecido, instituído pelo sistema tradicional de avaliação, provoca no professor inquietudes e no aluno uma certa desconfiança quanto ao resultado dessa avaliação (Rangel, 2003).

A maioria dos participantes mostrou-se favorável à utilização de uma metodologia de avaliação inovadora, como o portfólio; entretanto, citou-se que muitas vezes é preciso a realização de prova para instigar o aluno a estudar. O portfólio reflexivo foi considerado um instrumento inovador de avaliação, uma vez que busca deslocar a atenção para o processo vivenciado e a ampliação individual e coletiva do conhecimento.

\section{Sugestões}

Para aprimorar a utilização do portfólio, os estudantes mencionaram as sugestões: resposta do docente à leitura do portfólio, ou seja, não só o registro do estudante, mas também o do professor com considerações, elogios e sugestões.

(...) porque, queira ou não, mas quando o professor elogia, ele vai incentivando também.

Não só refletir as vivências, mas tudo o que o aluno achar importante e pertinente.

Proporcionar a troca dos portfólios, para que haja maior superação, preservando, entretanto, a privacidade; a apresentação desses portfólios perante a turma. Destacaram a importância de haver momento de troca de portfólios (socialização das experiências), entre os grupos do estágio, de forma a se 
pensar não em construção do portfólio individual, mas em construção de um portfólio do grupo.

(...) ter esse momento de troca, onde os alunos apresentassem uns aos outros o que é produzido, garantindo a privacidade das pessoas.

A apresentação prévia do professor sobre o portfólio busca mostrar de forma mais enfática sua importância, já que ao final desta experiência os relatos foram positivos.

(...) essa oportunidade que vocês tão dando para a gente é muito enriquecedora

(...) é uma alegria, e eu acho isso muito importante, porque foi tão bom para mim que eu imagino que tenha sido muito bom para as outras pessoas.

Sabe-se que algumas condições são necessárias para que o indivíduo possa usufruir, de forma mais plena, o seu potencial para criar e refletir. Características da própria personalidade e motivações pessoais influenciam a expressão da criatividade. Dessa forma, nos estágios supervisionados do curso de Odontologia, esses processos reflexivos tornaram-se bastante relevantes no contexto do aprendizado da atenção primária à saúde e da formação profissional. O estímulo à reflexão, à crítica e à liderança apreciativa ajudará o futuro profissional em suas decisões, tornando-o um cidadão e profissional consciente de seus direitos e deveres.

\section{Considerações finais}

O estudo sobre o uso do portfólio reflexivo foi muito importante para nortear uma análise da adoção do portfólio como instrumento de avaliação e acompanhamento das atividades nos estágios supervisionados da saúde coletiva. Essa avaliação subsidia o planejamento pedagógico dos componentes curriculares, apontando ainda alguns desafios a serem superados, especialmente em se tratando das dificuldades que os estudantes relataram na elaboração do portfólio e no entendimento dele como instrumento de diálogo, partilha, relato das vivências e articulação entre o teórico e o vivido no território.

É preciso construir processos avaliativos formativos que acompanhem o estudante de forma individual e deem a oportunidade a ele de se refazer nesse processo, para a construção do aprendizado (Marin et al., 2010a e 2010b). Isso tem sido um desafio para formação de profissionais de saúde, em função da complexidade dos problemas em saúde e da subjetividade de cada estudante. Além disso, implica um trabalho minucioso dos docentes, que pre- 
cisarão de mais tempo para leituras e releituras dos portfólios para uma orientação mais direcionada às necessidades de cada estudante.

Os resultados deste estudo demonstraram o portfólio como uma ferramenta importante no acompanhamento e avaliação do estudante nas vivências com base nas metodologias ativas de aprendizagem, tendo como cenário de aprendizagem a atenção primária em saúde. O portfólio estimula a reflexão e a crítica do vivenciado em campo na comunidade e oportuniza a reflexão da teoria e da prática, possibilitando ao docente e discente uma reinvenção no ensino e na aprendizagem. Embora apontem dificuldades na elaboração do portfólio, em especial pela experiência nova que o portfólio traz em sua vida acadêmica, percebeu-se que os estudantes refletem de forma individual o vivenciado coletivamente com seus próprios colegas de turma, com a comunidade, com o grupo de preceptores e docentes.

\section{Colaboradores}

Franklin Delano Soares Forte, Claudia Helena Soares de Morais Freitas, Talitha Rodrigues Ribeiro Fernandes Pessoa trabalharam na concepção e projeto de pesquisa, coleta, análise e interpretação dos dados, escrita, e revisão crítica do conteúdo do artigo; Camila Helena Machado da Costa responsabilizou-se pela análise e interpretação dos dados e escrita do artigo; Liberata Campos Coimbra, Dorlene Maria Cardoso de Aquino, Annatália Meneses de Amorim Gomes trabalharam na redação e revisão crítica. Declaramos que não há conflito de interesses na elaboração do trabalho. 
Resumen El estudio tuvo por objetivo comprender la percepción de estudiantes del curso de Odontología de la Universidad Federal de Paraíba sobre la utilización del portafolio como uno de los métodos de evaluación. Los datos referentes a 16 estudiantes fueron recolectados en 2011 mediante la técnica del grupo focal y se estudiaron por análisis de contenido. Se delimitaron entonces las categorías temáticas: definición, papel del discente-docente, metodologías activas, dificultades en la preparación del portafolio y sugerencias. Los estudiantes entienden al portafolio como un instrumento de diálogo entre docentes y discentes, por medio de los relatos de las vivencias en grupo en los equipos sociales y reflexiones individuales, en la construcción de conceptos y profundización teórica. Se concluye que los estudiantes observan al portafolio como una herramienta potente e innovadora para la formación profesional, siendo un instrumento de seguimiento del proceso de enseñanza-aprendizaje, por ser dialógico, interactivo, y brindar una oportunidad de aprendizaje activo.

Palabras clave formación; portafolio reflexivo; evaluación formativa; metodologías de enseñanza-aprendizaje.

\section{Notas}

1 Universidade Federal da Paraíba, Centro de Ciências da Saúde, Mestrado Profissional em Saúde da Família, Nucleadora UFPB, João Pessoa, Paraíba, Brasil.

$<$ fdsforte@terra.com.br>

Correspondência: Universidade Federal da Paraíba, Centro de Ciências da Saúde, Campus Universitário I, CEP 58051-900, João Pessoa, Paraíba, Brasil.

2 Universidade Federal de Campina Grande, Unidade Acadêmica de Ciências Biológicas, Patos, Paraíba, Brasil.

<camila_helena_@hotmail.com>

3 Universidade Federal da Paraíba, Departamento de Clínica e Odontologia Social, João Pessoa, Paraíba, Brasil.

$<$ talitha.ribeiro@yahoo.com.br>

4 Universidade Estadual do Ceará, Mestrado Profissional em Saúde da Família, Nucleadora UECE, Fortaleza, Ceará, Brasil.

<annatalia@saude.ce.gov.br>

5 Universidade Federal da Paraíba, Centro de Ciências da Saúde, Mestrado Profissional em Saúde da Família, Nucleadora UFPB, João Pessoa, Paraíba, Brasil.

$<$ chsmfreitas@hotmail.com>

6 Universidade Federal do Maranhão, Centro de Ciências Biológicas e da Saúde, Mestrado Profissional em Saúde da Família, Nucleadora UFMA, São Luís, Maranhão, Brasil.

<liberatacoimbra@gmail.com>

7 Universidade Federal do Maranhão, Centro de Ciências Biológicas e da Saúde, Mestrado Profissional em Saúde da Família, Nucleadora UFMA, São Luís, Maranhão, Brasil.

<dmcaquino@gmail.com> 


\section{Referências}

BARDIN, Laurence. Análise de conteúdo. Lisboa: Edições 70, 2009.

BRASIL. Ministério da Educação. Conselho Nacional de Educação. Câmara de Educação Superior. Diretrizes Curriculares Nacionais do Curso de Graduação em Odontologia. Diário Oficial da União, Poder Executivo, Brasilia, 4 de março, 2002. Seção 1, p. 10.

COTTA, Rosângela M. M.; MENDONÇA, Erica T.; COSTA, Glauce D. Portfólios reflexivos: construindo competências para o trabalho no Sistema Único de Saúde. Revista Panamericana de Salud Pública, Washington, v. 30, n. 5, p. 415-421, 2011.

GOMES, Andréia P. et al. Avaliação no ensino médico: o papel do portfólio nos currículos baseados em metodologias ativas. Revista Brasileira de Educação Médica, Rio de Janeiro, v. 34, n. 3, p. 390-396, 2010.

GONZÁLEZ, Alberto D.; ALMEIDA, Márcio J. Ativação de mudanças na formação superior em saúde: dificuldades e estratégias. Revista Brasileira de Educação Médica, Rio de Janeiro, v. 34, n. 2, p. 238-246, 2010.

MARCOLINO, Taís Q., MIZUKAMI, Maria G. N. Narrativas, processos reflexivos e prática profissional: apontamentos para pesquisa e formação. Interface: Comunicação, Saúde, Educação, Botucatu, v. 12, n. 26, p. 541-547, 2008.

MARIN, Maria J. S. et al. Aprendendo com a prática: experiência de estudantes da Famema. Revista Brasileira Educação Médica, Rio de Janeiro, v. 31, n. 1, p. 90-96, jan./abr. 2007.

MARIN, Maria J. S. et al. Aspectos das fortalezas e fragilidades no uso das metodologias ativas de aprendizagem. Revista Brasileira de Educação Médica, Rio de Janeiro, v. 34, n. 1, p. 13-20, 2010a.

MARIN, Maria J. S. et al. O uso do portfólio reflexivo no curso de medicina: percepção dos estudantes. Revista Brasileira de Educação Médica, Rio de Janeiro, v. 34, n. 2, p. 191-198, 2010b.

MINAYO, Maria C. S. O desafio do conhecimento: pesquisa qualitativa em saúde. 12. ed. São Paulo: Ed. Hucitec, 2010.

MITRE, Sandra M. et al. Metodologias ativas de ensino-aprendizagem na formação profissional em saúde: debates atuais. Ciência \& Saúde Coletiva, Rio de Janeiro, v. 13, Supl. 2, p. 2.133-2.144, 2008.

RANGEL, Jurema N. M. O portfólio e a avaliação no ensino superior. Estudos em Avaliação Educacional, São Paulo, v. 28, p. 145-160, 2003.

SILVA, Roseli F.; FRANCISCO, Marcos A. Portfólio reflexivo: uma estratégia para a formação em medicina. Revista Brasileira de Educação Médica, Rio de Janeiro, v. 33, n. 4, p. 562-570, 2009.

SILVA, Roseli F.; SÁ-CHAVES, Idália. Formação reflexiva: representações dos professores acerca do uso de portfólio reflexivo na formação de médicos e enfermeiros. Interface: Comunicação, Saúde, Educação, Botucatu, v. 12, n. 27 , p. 721-34, 2008.

STEWART, David W.; SHAMDASANI, Prem N; ROOK, Dennis. Focus groups: theory and practice applied social research methods series. 2. ed. Thousand Oaks: Sage, Newbury, 2007.

TANJI, Suzelaine; SILVA, Carmen M. S. L. M. D. As potencialidades e fragilidades do portfólio reflexivo na visão dos estudantes de enfermagem. Revista de Enfermagem UERJ, Rio de Janeiro, v. 16, n. 3, p. 392-398, 2008.

TEÓFILO, Tiago J. S.; DIAS, Maria S. A. Concepções de docentes e discentes acerca de metodologias de ensino-aprendizagem: análise do caso do Curso de Enfermagem da Universidade Estadual Vale do Acaraú em 
Sobral, Ceará. Interface: Comunicação, Saúde, Educação, Botucatu, v. 13, n. 30, p. 137-151, 2009.

VILLAS BOAS, Benigna M. F. O portfólio no curso de pedagogia: ampliando o diálogo entre professor e aluno. Revista Educação \& Sociedade, Campinas, v. 26, n. 90, p. 291-306, 2005.

Recebido em 16/06/2014

Aprovado em 29/06/2015 